\title{
Increased serum IL-36y levels are associated with disease severity in myasthenia gravis patients
}

\author{
Qiu-Xia Zhang, Yue Li, Shu-Min Jiang, Lin-Jie Zhang, Ming Yi, Jing Wang, Yuan Qi, Li Yang and \\ Chun-Sheng Yang ${ }^{*}$ (i)
}

\begin{abstract}
Background: Interleukin 36 (IL-36), as a gradually recognized cytokine, is involved in the occurrence and evolution of autoimmune diseases. Nevertheless, the relationship between myasthenia gravis (MG) and IL-36 is rarely reported.

Methods: We evaluated the serum levels of IL-36 (IL-36a, IL-36ß and IL-36y) by enzyme-linked immunosorbent assay (ELISA). Further, clinical parameters in 97 MG patients and 49 healthy controls (HCs) were carefully measured.

Results: Serum IL-36y levels were significantly elevated in the MG patients compared with the HCs $(p<0.0001)$. Compared to those in remission, patients in the acute phase exhibited higher levels of IL-36a and IL-36Y ( $p=0.038$ and $p=0.011$, respectively). Furthermore, patients with generalized MG (GMG) exhibited markedly higher serum IL$36 y$ levels than those with ocular MG (OMG) $(p=0.003)$.
\end{abstract}

Conclusions: The serum levels of IL-36y in patients with MG were increased and positively correlated with disease severity and may thus have potential as a serological MG marker.

Keywords: Biomarkers, Interleukin 36, Myasthenia gravis, Human

\section{Background}

Myasthenia gravis (MG) is an antibody-mediated inflammatory disease in which antibodies mainly destroy acetylcholine receptors (AChRs) at the junction between the nerve and muscle.

MG patients exhibit many other autoimmune antibodies [1-3], such as anti-lipoprotein-related protein 4 (LRP4), anti-titin, anti-ryanodine, anti-agrin, anti-cortain antibodies and anti-muscle-specific tyrosine kinase (MuSK), in addition to anti-AChR antibodies. Moreover, cytokines can regulate immune responses and contribute to MG pathogenesis, which impairs the transmission of neuromuscular junctions $[4,5]$.

\footnotetext{
* Correspondence: cyang01@tmu.edu.cn

Department of Neurology and Tianjin Neurological Institute, Tianjin Medical University General Hospital, 154 Anshan Road, Heping District, Tianjin 300052, China
}

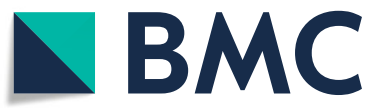

(c) The Author(s). 2020 Open Access This article is licensed under a Creative Commons Attribution 4.0 International License, which permits use, sharing, adaptation, distribution and reproduction in any medium or format, as long as you give appropriate credit to the original author(s) and the source, provide a link to the Creative Commons licence, and indicate if changes were made. The images or other third party material in this article are included in the article's Creative Commons licence, unless indicated otherwise in a credit line to the material. If material is not included in the article's Creative Commons licence and your intended use is not permitted by statutory regulation or exceeds the permitted use, you will need to obtain permission directly from the copyright holder. To view a copy of this licence, visit http://creativecommons.org/licenses/by/4.0/. The Creative Commons Public Domain Dedication waiver (http://creativecommons.org/publicdomain/zero/1.0/) applies to the data made available in this article, unless otherwise stated in a credit line to the data.
Interleukin 36 (IL-36), a new member of the IL-1 family, binds to the IL-36 receptor (IL-36R), which further activates both dendritic cells and CD4+ T lymphocytes, exerting a proinflammatory effect [6].

The latest evidence shows that IL-36 is involved in many autoimmune diseases, including systemic lupus erythematosus (SLE), atopic dermatitis and multiple sclerosis [7-12]. At present, the serum levels of IL-36 in MG patients are rarely reported. In our current research, we evaluated serum IL-36 levels in MG patients and their correlation with clinical characteristics.

\section{Methods}

We enrolled 97 MG patients who were treated at the Department of Neurology, Tianjin Medical University General Hospital between January 2016 and September 
2019. At the same time, 49 healthy controls (HCs), were recruited for the study. The patients with MG were diagnosed according to the typical clinical manifestations of weakness in voluntary muscles and those patients meet at least one of the following three criteria [13]: (1) positive anti-AChR antibody detection in serum; (2) repetitive motor nerve stimulation (RNS) decrement of $10 \%$ or greater; and (3) a positive response to intramuscular neostigmine. The exclusion criteria were as follows: (1) below 18 years of age and (2) history of previous inflammatory, neoplastic or other autoimmune disease. HCs were enrolled from the Health Care Center of our hospital. And those accompanied by autoimmune diseases, infectious diseases, heart diseases, lung diseases, kidney diseases were excluded.

The study was approved by the Ethics Committee of Tianjin Medical University General Hospital, and all the participants provided written consent.

\section{Sample collection}

Clinical data, including sex, age, anti-AChR antibody status, thymoma status, MG Foundation of America (MGFA) classification and MG-ADL score, were acquired from medical records in the electronic system of our hospital. In the acute phase, clinical evaluation and sample collection of 97 patients with MG was completed before treatment (intravenous immunoglobulin, plasma exchange or high-dose corticosteroids for 3-5 consecutive days). In total, 30 patients with MG were randomly selected, and specimens collected during remission were obtained. Simultaneously, general demographic data and fasting venous blood samples were collected from 49 $\mathrm{HCs}$ at our hospital. The samples were stored at $-80^{\circ} \mathrm{C}$.

\section{Serum IL-36 levels}

The serum levels of IL-36 $\alpha$, IL-36 $\beta$ and IL-36y were measured using human IL-36 $\alpha$, IL-36 $\beta$ and IL-36y enzyme-linked immunosorbent assay (ELISA) kits (R\&D Systems), respectively. All the steps were performed strictly in accordance with the kit instructions.

\section{Statistical analyses}

Statistical Program for Social Sciences (SPSS 22.0) was used for statistical analysis, and graphs were created

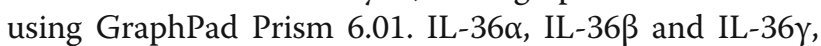
as continuous numerical variables, were compared between two groups using t-tests or the Mann-Whitney $\mathrm{U}$ test; gender, as qualitative data, was analyzed using the Fisher's exact test; and correlation analysis between serum IL-36 levels and MG-ADL scores was performed by Pearson correlation coefficient. $p<0.05$ was considered statistically significant.

\section{Results}

\section{Clinical characteristics}

The clinical features of the 97 MG patients and $49 \mathrm{HCs}$ are shown as follows: among these individuals, the numbers of women were $44(45.36 \%)$ and $30(61.22 \%)$, and the ages at sampling were $57.30 \pm 1.59$ years and $56.84 \pm$ 2.72 years, respectively. Similar to the findings of previous studies [14, 15], the results showed that anti-AChR antibodies were detectable in serum samples from 79 (81.44\%) of the MG patients, and there were 25 (25.77\%) MG patients with thymoma in the current study. The average MG-ADL score was $4.46 \pm 3.29$, and the distribution of the MG patients in the different MGFA classification categories (I: II: III: IV: V) was 40: 29: 19: 4: 5. In this study, we defined mild MG patients as those who were classified as I or II by MGFA, and the rest of the patients were considered to be severe MG patients.

\section{Serum IL-36 levels}

Markedly higher serum IL-36y levels were found in the MG patients than in the HCs $(p<0.0001$, Fig. 1a), but there were no significant differences in the serum IL$36 \alpha$ and IL-36 $\beta$ levels between the two groups $(p=0.325$ and $p=0.133$, respectively). When comparing different subtypes of MG, we observed that the serum IL-36y levels in ocular MG (OMG) patients were significantly lower than those in generalized MG (GMG) patients $(p=0.003$, Fig. 1a) but significantly higher than those in the HCs $(p=0.032$, Fig. 1a). Furthermore, as illustrated in Fig. 1b, the serum IL-36y levels in mild MG patients were significantly higher than HCs $(p=0.001)$, but lower than severe MG patients $(p=0.011)$. However, no significant differences in serum IL-36 $\alpha$ or IL-36 $\beta$ levels were found between the OMG and GMG patients $(p=$ 0.942 and 0.630 , respectively). Serum IL-36 $\alpha$ and IL-36 $\beta$ levels were equivalent between the mild and severe MG patients $(p=0.478$ and 0.989 , respectively). Furthermore, the serum IL-36 $\alpha$, IL-36 $\beta$ or IL-36y levels did not differ between anti-AChR antibody-positive and anti-AChR antibody-negative MG patients $(p=0.217,0.393$ and 0.829 , respectively). Serum IL-36 $\alpha$, IL-36 $\beta$ and IL-36y levels also showed no significant differences between MG patients with thymoma and those without thymoma $(p=0.234,0.167$ and 0.911 , respectively). Moreover, the MG patients in remission period had decreased serum IL-36 $\alpha$ and IL-36y levels compared to the acute phase $(p=0.038$ and 0.011 , respectively, Fig. 2). However, serum IL-36 $\beta$ levels did not significantly differ in MG patients between the acute and remission phases $(p=$ 0.918).

Moreover, we analyzed the correlation between serum IL-36 levels and MG-ADL score to discover possible intrinsic connections. The Pearson correlation results showed a weak relationship to be considered of any 

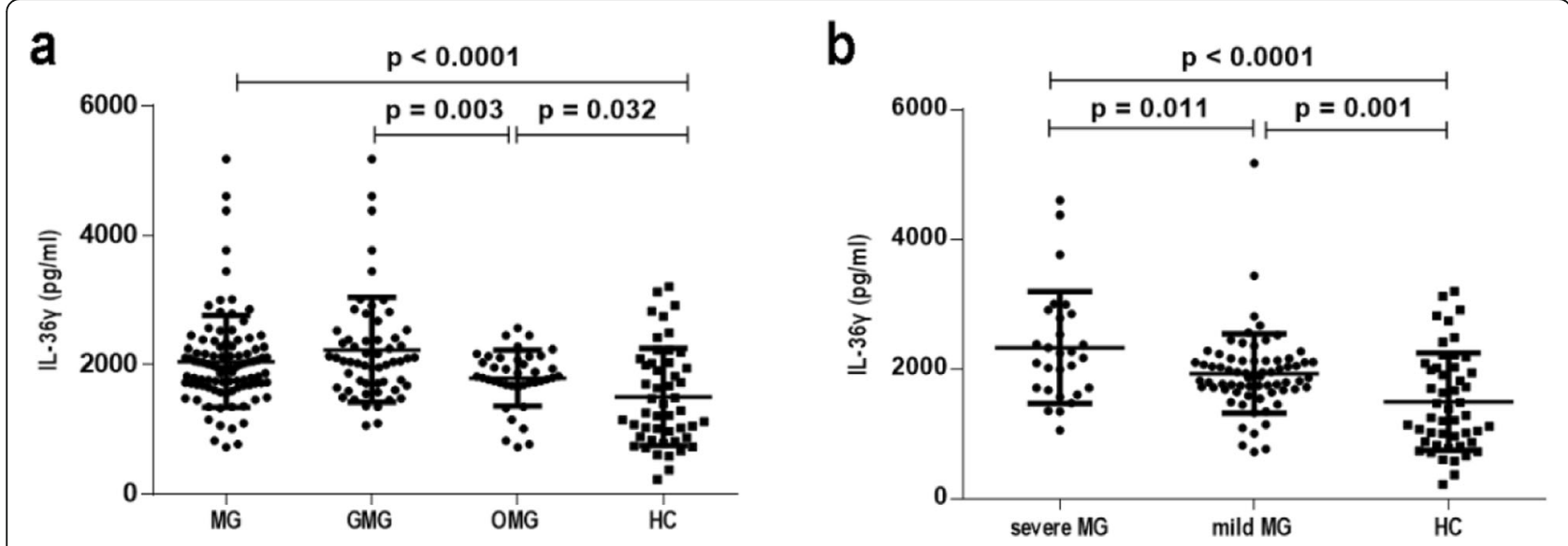

Fig. 1 Serum IL-36y levels in myasthenia gravis (MG) patients and healthy controls (HCs). a Comparison of serum IL-36y levels among MG patients, generalized MG (GMG) patients, ocular MG (OMG) patients and HCs. b Comparison of serum IL-36y levels among severe MG patients, mild MG patients and HCs

relevant value between the serum IL-36y levels and the MG-ADL score in MG patients $(\mathrm{r}=0.215, p=0.035)$. Furthermore, serum IL-36 $\alpha$ or IL-36 $\beta$ levels and the MG-ADL score were not correlated $(\mathrm{r}=0.035, p=0.973$; $\mathrm{r}=0.078, p=0.451$ ).

\section{Discussion}

Numerous studies have indicated that IL-36 is involved in the immune inflammatory response and may play critical roles in autoimmune diseases. However, the specific mechanism of IL-36 in MG is still rarely reported. In this study, we clarified that serum IL-36y levels were elevated in MG patients compared with HCs. The clinical manifestations of patients with GMG are more serious, which can manifest as weakness of the limbs, trunk, throat and respiratory muscles. There were $57 \mathrm{pa}$ tients with GMG, including 28 severe MG patients in current study, and comparisons of subtypes of MG revealed that GMG and severe MG exhibited elevated levels of IL-36y. Moreover, our study demonstrated that serum IL-36y levels were decreased during remission. In a few patients with MG, the serum levels of IL-36y did not decrease during the remission period, but even increased. Which may be due to individual differences, but the overall was still reduced.

As a factor promoting the inflammatory response, IL36 is involved in the inflammatory process and accelerates the downstream inflammatory response, which has been illustrated in many diseases. A clinical trial of 72 systemic lupus erythematosus (SLE) patients and 63 HCs showed that serum IL-36 $\alpha$ and IL-36y levels were increased in SLE patients and related to systemic lupus erythematosus disease activity index (SLEDAI) scores, which suggest that IL-36 is associated with SLE disease

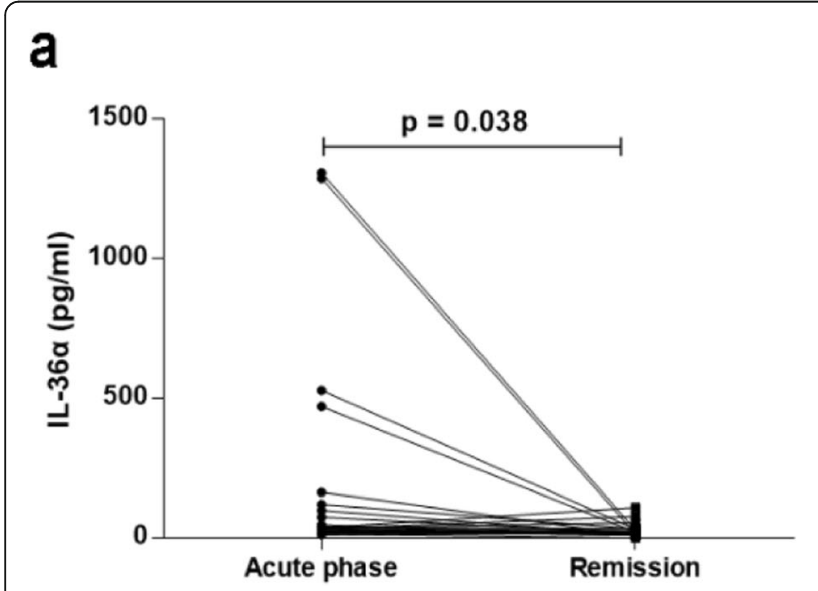

b

Fig. 2 Serum IL-36a and IL-36y levels in myasthenia gravis (MG) in the acute and remission phases. a Comparison of serum IL-36a levels between MG patients in the acute and remission phases. $\mathbf{b}$ Comparison of serum IL-36y levels between MG patients in the acute and remission phases 
activity [14, 15]. Moreover, another study showed that IL-36 $\alpha$ and IL-36y were expressed to promote the development of inflammation by inducing the production of chemical factors in inflammatory bowel disease [10]. Similar to the above diseases, MG is also an antibodymediated, cellular immunity-dependent, complementassociated, cytokine-mediated autoimmune disease. Therefore, IL-36 is likely to play a similar role in MG.

Although many studies have explored the pathogenesis of IL-36, we know very little about the specific mechanisms of IL-36, and thus, IL-36 remains to be further explored. The latest demonstrates that IL-36 is secreted by not only peripheral blood cells such as macrophages, DCs and T cells but also keratinocytes and mucosal epithelial cells [10]. Moreover, studies by Towne et al. [16] have shown that IL-36 performs its role through binding to IL-1 receptor-related protein 2 (IL-1Rrp2), which activates the pathway leading to NF-kB. IL-36 has also been shown to activate the MAPK pathway, which is similar to the signaling pathways of IL- $1 \beta$ and IL-18, in NCI/ ADR-RES cells. On the one hand, IL-36 stimulates DCs and induces $\mathrm{CD} 4+\mathrm{T}$ cells to differentiate into Th1 cells $[6,17]$. Th1 cells produce IL-2 and IFN- $\gamma$, perform helper functions to support particular immunoglobulin classes and subclasses. An imbalance among Th1, Th2 and Th17 cells will participate in the pathological process and aggravate the progression of MG diseases [18-21], so IL-36 may also be involved in the pathogenesis of MG through these cells. On the other hand, IL36 can greatly promote the secretion of inflammatory factors, including IL-1, IL-6, IL-8, IL-12, IL-18, IL-23, IFN- $\gamma$, TNF- $\alpha$ and granulocyte-macrophage colonystimulating factor, by DCs, macrophages and keratinocytes $[16,22,23]$. Emerging data have shown that these factors also contribute to the pathological process of MG [24-29]; for example, in a study of AChRimmunized IL- $6^{-1-}$ mice, decreases in the anti-AChR antibody titer and C3 levels, and a relatively low proportion of the mice developed experimental autoimmune MG [29]. Consistent with this study, another study found that anti-IL-6 antibodies could inhibit experimental autoimmune MG by reducing the anti-AChR antibody titer and the number of $\mathrm{B}$ cells and downregulating the expression of Th17-related genes [30]. Similarly, other studies have clarified that the application of antiTNF- $\alpha$ antibodies can delay disease onset and lead to disease presentation as only mild muscle weakness [24], and we thus hypothesize that serum IL-36 is involved in the pathogenesis of MG through the interaction of these factors. In conclusion, IL-36 is likely to participate in the pathological process of MG through the abovementioned immune cells and cytokines.

The limitations of this study need to be noted. First, because this study is a cross-sectional study, it is prone to bias. Second, this study enrolled 97 MG patients and $49 \mathrm{HCs}$ in a single-center, small-sample study. Third, though serum samples from patients were collected before treatment, some patients with MG were on oral steroids, and its effect on results is unknown. In the future, we will continue to expand the sample size to discover additional valuable information about IL-36 and MG.

\section{Conclusions}

Our results indicate that IL-36y is positively correlated with the severity of MG. Additionally, IL-36y may be involved in the immunopathological process of MG, suggesting that it may be a potential immune marker for MG.

\section{Abbreviations}

IL-36: Interleukin 36; MG: Myasthenia gravis; ELISA: Enzyme-linked immunosorbent assay; HCs: Healthy controls; AChRs: Acetylcholine receptors; MuSK: Muscle-specific tyrosine kinase; GMG: Generalized MG; OMG: Ocular MG; MG-ADL: MG activities of daily living; SLE: Systemic lupus erythematosus; RNS: Repetitive motor nerve stimulation; MGFA: MG Foundation of America; EAMG: Experimental autoimmune MG

\section{Acknowledgements}

We thank Dr. ANGELA VINCENT for providing plasmids for AChRs and we are also very grateful to the patients who participated in the study.

\section{Authors' contributions}

CSY and LY participated in study design. QXZ, YL, SMJ, LZ, MY, QY and JW participated in data collection. QXZ and YL participated in statistical analysis. All authors read and approved the final manuscript.

\section{Funding}

The study was supported by the National Natural Science Foundation of China (grant numbers: 81771363 and 81571172). The sponsor played no role in the design of the study and collection, analysis, and interpretation of data. Also, the sponsor was not involved in writing this manuscript.

\section{Availability of data and materials}

The datasets used and/or analysed during the current study are available from the corresponding author on reasonable request.

\section{Ethics approval and consent to participate}

The study was approved by the Ethics Committee of Tianjin Medical University General Hospital and committee's reference number was IRB2019WZ-126. Written informed consent is obtained from all participants prior to inclusion.

\section{Consent for publication}

Not applicable.

\section{Competing interests}

The authors declare that they have no competing interests.

Received: 20 November 2019 Accepted: 10 August 2020 Published online: 19 August 2020

\section{References}

1. Leite MI, Waters P, Vincent A. Diagnostic use of autoantibodies in myasthenia gravis. Autoimmunity. 2010;43:371-9.

2. Yan $M$, Xing GL, Xiong WC, Mei L. Agrin and LRP4 antibodies as new biomarkers of myasthenia gravis. Ann N Y Acad Sci. 2018;1413:126-35.

3. Illa I, Cortes-Vicente E, Martinez MA, Gallardo E. Diagnostic utility of cortactin antibodies in myasthenia gravis. Ann N Y Acad Sci. 2018;1412:90-4.

4. Uzawa A, Kawaguchi N, Himuro K, Kanai T, Kuwabara S. Serum cytokine and chemokine profiles in patients with myasthenia gravis. Clin Exp Immunol. 2014;176:232-7. 
5. Uzawa A, Kanai T, Kawaguchi N, Oda F, Himuro K, Kuwabara S. Changes in inflammatory cytokine networks in myasthenia gravis. Sci Rep. 2016;6:25886.

6. Gunther S, Sundberg EJ. Molecular determinants of agonist and antagonist signaling through the IL-36 receptor. J Immunol. 2014;193:921-30.

7. Chu M, Wong CK, Cai Z, Dong J, Jiao D, Kam NW, et al. Elevated expression and pro-inflammatory activity of IL-36 in patients with systemic lupus erythematosus. Molecules. 2015;20:19588-604.

8. Mai SZ, Li CJ, Xie XY, Xiong H, Xu M, Zeng FQ, et al. Increased serum IL36alpha and IL-36gamma levels in patients with systemic lupus erythematosus: association with disease activity and arthritis. Int Immunopharmacol. 2018;58:103-8.

9. Russell SE, Horan RM, Stefanska AM, Carey A, Leon G, Aguilera M, et al. IL36alpha expression is elevated in ulcerative colitis and promotes colonic inflammation. Mucosal Immunol. 2016;9:1193-204.

10. Nishida A, Hidaka K, Kanda T, Imaeda H, Shioya M, Inatomi O, et al. Increased expression of interleukin-36, a member of the interleukin-1 cytokine family, in inflammatory bowel disease. Inflamm Bowel Dis. 2016;22: 303-14

11. Otobe S, Sugaya M, Nakajima R, Oka T, Takahashi N, Kabasawa M, et al. Increased interleukin-36gamma expression in skin and sera of patients with atopic dermatitis and mycosis fungoides/Sezary syndrome. J Dermatol. 2018;45:468-71.

12. Alsahebfosoul F, Jahanbani-Ardakani H, Ghavimi R, Sedaghat N, Etemadifar M. Serum level of interleukin 36 in patients with multiple sclerosis. J Immunoassay Immunochem. 2018;39:558-64.

13. Allen JA, Scala $S$, Jones HR. Ocular myasthenia gravis in a senior population: diagnosis, therapy, and prognosis. Muscle Nerve. 2010;41:379-84.

14. Vincent A, Newsom-Davis J. Acetylcholine receptor antibody as a diagnostic test for myasthenia gravis: results in 153 validated cases and 2967 diagnostic assays. J Neurol Neurosurg Psychiatry. 1985;48:1246-52.

15. Kondo K, Monden Y. Thymoma and myasthenia gravis: a clinical study of 1,089 patients from Japan. Ann Thorac Surg. 2005;79:219-24.

16. Towne JE, Garka KE, Renshaw BR, Virca GD, Sims JE. Interleukin (IL)-1F6, IL1F8, and IL-1F9 signal through IL-1Rrp2 and IL-1RACP to activate the pathway leading to NF-kappaB and MAPKs. J Biol Chem. 2004;279:13677-88.

17. Vigne S, Palmer G, Martin P, Lamacchia C, Strebel D, Rodriquez E, et al. IL-36 signaling amplifies Th1 responses by enhancing proliferation and Th1 polarization of naive CD4+ T cells. Blood. 2012:120:3478-87.

18. Mu L, Sun B, Kong Q, Wang J, Wang G, Zhang S, et al. Disequilibrium of T helper type 1,2 and 17 cells and regulatory T cells during the development of experimental autoimmune myasthenia gravis. Immunology. 2009;128: e826-36.

19. Chen P, Li Y, Huang H, Li Y, Huang X, Chen Z, et al. Imbalance of the two main circulating dendritic cell subsets in patients with myasthenia gravis. Clin Immunol. 2019:205:130-7.

20. Skeie GO, Bentsen PT, Freiburg A, Aarli JA, Gilhus NE. Cell-mediated immune response against titin in myasthenia gravis: evidence for the involvement of Th1 and Th2 cells. Scand J Immunol. 1998;47:76-81.

21. Saoudi A, Bernard I, Hoedemaekers A, Cautain B, Martinez K, Druet $P$, et al. Experimental autoimmune myasthenia gravis may occur in the context of a polarized Th1- or Th2-type immune response in rats. J Immunol. 1999;162: 7189-97.

22. Gabay C, Towne JE. Regulation and function of interleukin-36 cytokines in homeostasis and pathological conditions. J Leukoc Biol. 2015;97:645-52.

23. Dietrich $D$, Martin $P$, Flacher $V$, Sun $Y$, Jarrossay D, Brembilla $N$, et al. Interleukin36 potently stimulates human M2 macrophages, langerhans cells and keratinocytes to produce pro-inflammatory cytokines. Cytokine. 2016;84:88-98.

24. Duan RS, Wang HB, Yang JS, Scallon B, Link H, Xiao BG. Anti-TNF-alpha antibodies suppress the development of experimental autoimmune myasthenia gravis. J Autoimmun. 2002;19:169-74.

25. Wang W, Milani M, Ostlie N, Okita D, Agarwal RK, Caspi RR, et al. C57BL/6 mice genetically deficient in IL-12/IL-23 and IFN-gamma are susceptible to experimental autoimmune myasthenia gravis, suggesting a pathogenic role of non-Th1 cells. J Immunol. 2007:178:7072-80.

26. Yang H, Tuzun E, Alagappan D, Yu X, Scott BG, Ischenko A, et al. IL-1 receptor antagonist-mediated therapeutic effect in murine myasthenia gravis is associated with suppressed serum proinflammatory cytokines, C3, and anti-acetylcholine receptor IgG1. J Immunol. 2005;175:2018-25.

27. Villegas JA, Bayer AC, Ider K, Bismuth J, Truffault F, Roussin R, et al. II-23/ Th17 cell pathway: a promising target to alleviate thymic inflammation maintenance in myasthenia gravis. J Autoimmun. 2019;98:59-73.
28. Jander S, Stoll G. Increased serum levels of the interferon-gamma-inducing cytokine interleukin-18 in myasthenia gravis. Neurology. 2002;59:287-9.

29. Deng C, Goluszko E, Tuzun E, Yang H, Christadoss P. Resistance to experimental autoimmune myasthenia gravis in IL-6-deficient mice is associated with reduced germinal center formation and C3 production. J Immunol. 2002;169:1077-83.

30. Aricha R, Mizrachi K, Fuchs S, Souroujon MC. Blocking of IL-6 suppresses experimental autoimmune myasthenia gravis. J Autoimmun. 2011;36:135-41.

\section{Publisher's Note}

Springer Nature remains neutral with regard to jurisdictional claims in published maps and institutional affiliations.
Ready to submit your research? Choose BMC and benefit from:

- fast, convenient online submission

- thorough peer review by experienced researchers in your field

- rapid publication on acceptance

- support for research data, including large and complex data types

- gold Open Access which fosters wider collaboration and increased citations

- maximum visibility for your research: over $100 \mathrm{M}$ website views per year

At BMC, research is always in progress.

Learn more biomedcentral.com/submissions 